\title{
Digital Transformation in Marketing Mobile Phones Industry: Evaluating Marketers Strategies for Cross- Cultural Advertisements
}

\author{
Rabiya Arshad \\ Riphah International University, PAKISTAN \\ (iD) 0000-0002-0121-5463 \\ Moazzam Naseer \\ Riphah International University, PAKISTAN \\ (iD) 0000-0002-6214-6633 \\ Moazzam.naseer@riphah.edu.pk
}

\author{
ARTICLE INFO \\ Received: 18 May 2019 \\ Accepted: 30 May 2019 \\ Published: 18 July 2019 \\ DOI: https://doi.org/10.29333/ojcmt/5841 \\ ABSTRACT
}

In upcoming time, media science will be more rapidly growing and developing than today in almost every field whether it will be communication, marketing, advertising, finance or arts. These developments and advancements in technologies make things much easier, cheaper and effective for the people. In present time, the marketing and advertising of products, goods and services has become necessity for everybody's daily life whether it be the customer, producer or trader but in near future, the standard way of product advertising will be transformed from visual communication to digital visual communication. This digital visual communication will have great impact on marketing and advertising and would have many beneficiaries for the marketers and advertisers. Nowadays, the key elements used in visual communication for advertising of products are line, color, shapes, images, typography, space, size and scale. The latest trends of visual communication are composed of combination of images and text. As in visual communication, images are more powerful communicator than text so, the trends of today's advertisement design are composed with more images and short text. The evolution of digital visual culture has all the aspects of visual culture but with higher quality and improved level of communication. With the help of improved visual content quality and short texts, advertisers gain more publicity, attraction and acceptance of wider audience toward the product advertisement. Currently the main problem that marketers and advertisers are facing in communication process at international level in marketing and advertising of products are cross cultural effects like language, literacy, religion, arts etc. This research is conducted for the purpose to analyze the effect of digital culture on visual communication through qualitative content analysis. Here the question arises in almost everyone's mind that can digital visual culture overcome cross cultural effects on marketing and advertising of products?

Keywords: digital transformation, visual communication, advertising, cross-culture, digital visual communication, products 


\section{BACKGROUND}

Visual Communication started around 40,000 years back when even writing was not yet invented but paintings of that time, made on rocks and caves, were lately found. Therefore, we can say that it has been a part of our world since beginning (Lovely, 2012). After the invention of writing, many illuminated scriptures were presented to show artwork. The first fine art movement of visual communication was done in avant-garde period of $20^{\text {th }}$ century. Fast forward, we reached the time of modernism in mid-20th century. In this era, many advancements were occurred in visual communication. From 2000 onwards, modern computer era. After the invention of computer many major developments and advancements of new technologies and strategies occurred in the field of science which not only bring people closer but also globally connected to each other especially after the arrival of internet (Jose, 2016). These advancements in technologies made communication process between different countries easy for the people to stay connected with each other. Visual Communication is mainly used in advertising of products, good and services to show company's devotion to their customers. It is the way of expressing and sharing feelings, thoughts, ideas and messages through the correct placement and combination of visual elements. The basic elements of design are line, shapes, color, space, size, scale, pattern and texture. The principles of design are: balance, proportion, harmony, color interaction and rhythm (Ken \& Heather, 2015).

Since from the year 2000, many changes and advancements have been happening in technology and design trends of graphic design till today and many are still in progress. These advancements make it easy, efficient and effective in terms of quality and quantity on professional grounds. The most common software's that designers used today for graphic designing are Adobe Illustrator (1988), Photoshop (1988), Adobe Indesign (1994) and Corel Draw (1989), Adobe Dreamweaver (1997) for web design while Adobe Premiere pro (1991), After Effects (1994) and Adobe Flash Professional (1996) for video ads have also been used for it. Later many versions of these softwares were developed that add some new features with the existing ones. In 2002, Adobe Creative Suit were developed by Adobe Inc that involves almost all the above mentioned softwares and some others in one software except Corel Draw as it belongs to other company. However, Inkscape are also be used for commercial ads by the expert graphic designers. With the help of these softwares advertisers make different designs of banners ads, posters, logos, flyers and stationary items to promote their products and expand their business at international level (Wikipedia).

The history of advertising industry starts back to $19^{\text {th }}$ century. The main purpose of advertising is to share information about goods, products and services of different marketing agencies through various media. The most common media used for advertising are print and broadcast. Print media (1906) includes magazines, newspaper, posters, flyers or brochures while broadcasting advertisements includes internet (banner ads, social networking marketing and rich media ads), television (commercial ads in the form of videos) and radio (voice ads) dates back in 1994. Print media starts with the newspaper publishing. The first print ad was "kodak story" then in 1917 tobacco fund ad was published and the first film poster was published in 1938. Nowadays, advertising of products is not only done at national level but also at international level. International advertising is a strategy of developing communication and business between different countries. It is the best way to grab large number of customers and market audience. In today's fast and competitive world advertising of products, goods and services has become necessity for everybody's daily life whether it be the customer, producer or trader. It helps 
to create awareness about the product's price and specifications in customers to choose and buy the product which is best for them (Prachi, 2013). Thus, advertising is not only beneficial for the customers but also beneficial for the companies that are producing and selling the products but it has gone through many difficulties like language, literacy and religion in the communication process. This communication process occurs on three stages: input message, processed message and deliver output (Dyer, 2008). After the arrival of internet, digital advertising became popular and reached its growth and acceptance to the highest point in social media era. The origin of social media began with the birth of world wide web. The first social media website was developed in 1997 known as Six Degrees and it lasted until 2000 with the predecessor of other sites that we used today (Karla, 2016). Nowadays social media is used as a business strategy to endorse and expand their business, gain more audience and engage their consumers with themselves. The main reason of gaining popularity of social media advertising is the increase use of mobile phones technology and its apps downloading systems (Kevin, Sarah, \& Christopher, 2011).

\section{INTRODUCTION}

Visual communication is an essential component of any nation. Its main purpose is to communicate and promote products, business, culture, art, media and many other things through different visuals both at national and international level. Here the term visual can be defined as pictures, texts, colors, posters or a piece of film to show and explain anything that we can see in the world around us. It is completely depending on our eyesight (Claudia, 2017). Nowadays, visual communication is use for five different types of advertisements i.e. Print, broadcast, product/brand integration, outdoor and digital advertising (Neil, 2018). After the invention of computer many major developments and advancements of new technologies and strategies occurred in the field of science which not only bring people closer but also globally connected to each other especially after the arrival of internet (Jose, 2016). These advancements in technologies made communication process between different countries easy for the people to stay connected with each other. The process of communicating goods and services' information between multiple countries is not simple and easy because it occurs between two different nations and every nation has its own culture and values. Thus, it has gone through many cultural difficulties like language, literacy, religion, art etc. in the communication process. This communication process occurs on three stages: input message, processed message and deliver output (Hanisha, 2017) and at each stage barriers might affect the transmission of message which ultimately results in miscommunication. At first stage there is a possibility that if message is not carefully observed and selected. At the second stage of encoding message care needs to be taken of translation and language that it should be understandable by the target audience. Then at the third stage carefully selected the media channel through which your message is being delivered to the target audience. (Dyer, 2008). An attractive and effective advertisements is based on elements (line, shapes, color, space, size, scale, pattern and texture) and principles (balance, proportion, harmony, color interaction and rhythm) of design. Every single design is made for the purpose of communication, so it keeps some kind of message and information in it whether the design is good or bad (Graphic, 2014). The latest trends of visual communication are composed of combination of images and text. As in visual communication, images are more powerful communicator than text so, the trends of today's advertisement design are composed with more images and short text (Claudia, 2017). In this paper, researcher analyzes the products advertising 
at international level through digital media and see that can digital transformation in visual communication overcome cross-cultural effects on product advertising? With the passage of time our world has been globally transforming towards technological change of digitization especially in media and communication industry. The evolution of digital visual culture has all the aspects of visual culture but with higher quality and improved level of communication. After the evolution of internet and social media, users are able to interact with others and it also helps to develop communication between advertisers and their specific audiences (Kevin, Sarah, \& Christopher, 2011). Digital advertising helps the advertisers to communicate with their consumers online by taking their feedbacks on advertisements of their products, goods and services with the help of social media (Warren, 2018). This kind of conversation between advertisers and consumers make the advertising as a two-way communication which is beneficial for both parties and it also helps to overcome many cross-cultural issues occurred in visual communication advertisements. Before the transformation of digitization, advertising was a one-way communication process that directly came from advertisers to target audience and the audience has nothing to do with advertisements but after the digital conversion the audience is able to give feedback and remarks on advertisements which will help the advertisers to improve their ads according to audience needs and desires (Kevin, Sarah, Christopher., 2011). In this modern era, there are many social media platforms that are used for advertising and business expansion purposes such as Facebook, Twitter, Instagram, LinkedIn, Snapchat, Pinterest, Tumblr, Spotify and Foursquare. (Dijk, 2013).

\section{LITERATURE REVIEW}

Visual communication has been a part of our world since beginning. The history of design starts from late $19^{\text {th }}$ century and its main purpose is communication. It is a type of non-verbal communication in which we share information and ideas to communicate and promote products, good, services, business, culture, art, media and many other things through different visuals at national and international level. Thus, we can say that it is an essential component of every nation. Here the term visual can be defined as pictures, charts, maps, texts, colors, posters or a piece of film to show and explain anything that we can see in the world around us. It is completely depending on our eyesight (Claudia, 2017). Nowadays, design is used in different user experience fields such as interaction design, visual design, motion graphics, architecture, marketing, prototype industrial design and even sound design. Hence, the definitions and role of design is also defined differently in every user experience field by different scholars. According to Issey Miyake (Fashion Designer), "design is not for philosophy, It's for life" and Economic scholar Herbert A Simon's saying about design is, "To design is to devise courses of action aimed at changing existing situations into preferred one" while according to an Architect scholar Eero Saarinen saying is, "Always design a thing by considering it in a larger context" but according to International Council Societies Of Industrial Design, "Design is a creative activity whose aim is to establish the multi-faceted qualities of objects, processes, services, and their systems in whole lifecycles". In visual communication, design plays an important role and it is defined as the set of tools and creative processes that combines the art and technology to communicate ideas and to express the aesthetics and functions of products through different visuals (Reo, 2012). Every single design is made for the purpose of communication so, it keeps some kind of message and information in it whether the design is good or bad (Graphic, 2014). To analyze the attraction of consumer towards the ad design, we should first understand the importance of design and its elements. As 
these elements makes the design good or bad in the eyes of consumers (Daniel T, 2016). According to Ashish, Ambudi and Brijesh research 75\% of information processing in our brain is basically visuals.

\section{ELEMENTS AND PRINCIPLES OF VISUAL COMMUNICATION AND ITS ADVANTAGES}

The history of design starts from late $19^{\text {th }}$ century. The elements and principles of design plays an important role in an effective and attractive advertisement design. Thus, the key elements used in visual communication for advertising of products are line, color, shapes, images, typography, space, size and scale. Every element of design has its own identity and characteristic. The basic nature of line has only one dimension but the combination of lines make shapes, creates motion, space, perspective and texture. Lines can be vertical, horizontal and diagonal (Hawaii.edu). Color is another very important element in design as it shows the mood and narrates the image or design that what does it say. It is made up from spectrum of light. Every color has its own meaning and describe some kind of mood in it (Graphic, 2014). Shapes are made up of combination of lines. They are geometric and abstract in nature. The geometric figures are square, rectangle, triangle, pentagon, circle, oval etc. Shapes also create movement in a picture and describes the mood of a picture and it also develop a new element forms which refers to 3D effect (Johny, 2010). Size generally refers to length, width and depth of the object. Whereas scale refers to the comparative relation of two or more object with respect to sizes. The correct use of size and scale of objects make the design interesting, meaningful and brings variety in design. It brings a fresh look and develop new way to design while type refers to the text style and size. In graphic designing it is also known as typography. The basic properties of text style include: font style or font name, font size and font color. It is also used for visual communication (Graphic, 2014). Every design stands on the design elements and design principles. A good design is about how you puts the right combination of elements and principles of design. If you put the right combination of these design elements but do not follow the principles of design correctly then it will definitely affect your design and give the result of either unclear message or inappropriate design. And if you use the principles of design correctly but the elements are not properly used then it will give you the same unclear result because elements and principles work side by side and carry equal importance. So, it is necessary to take good care of elements and principles both while making design. In advertisement design, as images and pictures are easier to understand and take less time in processing by the brain than words or texts so images are more powerful communicator than text or verbal languages. Thus, we can say that verbal processing takes more time and difficult for the brain than visual processing because the process of words and text has been limited in language center by the brain (Ashish, Ambudi, \& Brijesh, 2012). However, visual advertisements are more reliable and prominent because our mind get it easily and it is not limited by any cultural factor but one should always keep in mind your target audience's culture, tastes and viewpoints while making advertisement design (Mydee, 2018).

\section{CONSUMERS ATTITUDE AND PERCEPTION TOWARDS ADVERTISEMENT DESIGN}

The consumers attitude and perception towards ad design plays an important role in successful advertisement campaign as it shows the consumers response and buying behavior towards the ad design (Juan \& Ruiz, 2008). The previous researchers describe 
two main level of consumers response towards advertisement design i.e. cognitive and emotional response. The cognitive response is based on three different categories namely, aesthetic impression, semantic interpretation, and symbolic association. The first level of consumer response is aesthetic impression and it can be defined as anything that has the ability to gain attraction and desire of consumers sensory properties and the consumers cognitive response of aesthetic impression. Here the word aesthetic can be the beauty, appeal and attractiveness of the product. Aesthetic products deal with sensitivity of the product that how its appearances, feel, touch, perception, taste and smell (Daniel T, 2016). The second level of consumers response is Sematic interpretation response. It can be defined as interpretation of product's functions, mode of use and qualities such as performance, efficiency, function and ergonomic. The third level of consumer response is symbolic association and it can be defined as a difference between the product appearance and consumer's experience about the product (Fenko \& Galetzka, 2015). The emotional response of consumers is based on psychological reaction which shows feeling, mood and emotions, to product's appearance. Emotional response is based on five different groups, namely social, interest, instrumental, aesthetic and surprise (Juan \& Ruiz, 2008). In this digital era, the consumers attitude and response towards advertisements design is mainly based on visual elements, brand reputation and culture. Brand reputation plays an important role in advertising because it is a part of marketing strategy to promote a product or brand and social media plays a key role in gaining success, popularity and larger customer audience. Thus, social media also boosts sales of marketers and increases the purchase intention of target audience's (Faheemullah \& Usman, 2017). According to Andrew Stephen's research, approximately one third of global advertising is done on digital platforms. Now people are moving towards digital or social media and exposing themselves more and more on it for getting more information and developing new relations with other peoples. Thus, it also open new ways of success and helps them to become popular in market, expand their business and increase the engagement interaction with large number of people. With the help of social media, now customers first observe the market value and reputation of brand on social media through the consumers' likes, tweets, comments, reviews and feedback before purchasing any product from market (Andrew, 2016). Advertisers also use visual content with aesthetic appeal in their ads to seek attention and attraction of consumers (Eiman \& Passant, 2015).Culture also plays an important role in advertising as it educates the consumers to what and how they should perceive the visual message, when expose to an image or advertisement design (Juan \& Ruiz, 2008). Culture can be defined as the language, habits, arts, music, cuisine and religion of some specific group of people (Sukesh, 2011). Every nation has its own culture. Thus, the advertising should be done according to the country's regulations and culture. Here we observe three countries culture, i.e United States, Pakistan and China.

\section{CROSS CULTURAL DIFFERENCES IN INTERNATIONAL ADVERTISING}

There are seven main types of advertising (brand advertising, commerce and retail advertising, corporate advertising, advertising with feedback, political advertising, business advertising and social advertising) and four main functions of advertising (economical function, social function, marketing function and communication function. In this study researcher analyzes only brand advertising on Facebook with respect to marketing and communication function. The process of communicating information, 
goods and services between multiple countries is commonly known as international advertising but it is not that easy and simple as it has to gone through many difficulties like language, literacy, religion etc. in the communication process. This communication process occurs on three stages: input message, processed message and deliver output and at each stage barriers might affect the transmission of message which ultimately results in miscommunication. At first stage the producers thought about the message or information. At second stage the message should carefully observed that whether it fulfill the requirements of people of different cultures. At third stage media channel should be selected to deliver the message to target audience. At first stage there is a possibility that if message is not carefully observed and selected. At the second stage of encoding message care needs to be taken of translation and language that it should be understandable by the target audience. Then at the third stage carefully selected the media channel through which your message is being delivered to the target audience. There are many advantages of international advertising like expansion of business, growing power and wealth, growing acceptance of your brand worldwide and gain the attraction of more customers. But these things only work well when you make an ad that fulfill the cultural requirements of different countries. So, cultural factors play an important role in international advertising both as communication process or business practice (Susan \& Samneul, 2003). The cultural differences are the most common issue in international advertising. In this paper we observe the advertising culture of China, Pakistan, India and United States (Sukesh, 2011). The advertising culture of China, Pakistan, India and United States are very different from each other in terms of values, thoughts and languages. China and Pakistan follow eastern culture in advertising, India follows mixture of eastern and western culture in advertising whereas United States follow western culture in advertising (UK Essays, 2018). Eastern people belong to Asia and Middle East countries. Whereas western people belong to Europe and North America. The main reason of difference in cultural advertising are the values that they learn from their home and society. The values of eastern culture are inflexible in traditions and the people are conservative in nature, the idea of arrange marriages are common among them, Family support system is based on Elders, all decisions are taken by them and children obey the elder decisions. Whereas values of western culture are more liberal in their nature, traditions, feelings and thoughts, also individuals are free to take their own decisions and love marriages are common among them. For example, if people of west are angry, their anger are shown on their face whereas people of east hide their anger feeling to show good manners (Michael, 2018).

\section{DIGITAL TRANSFORMATION IN VISUAL COMMUNICATION}

Visual communication has been developing since beginning and many of it are still in progress (Ubani, 2016). After the year 2000, the digital media arrives and start developing in almost every field of the world. Thus, the visual communication has also been globally transformed towards digitization (Edward \& Bobby, 2018). This digital visual communication will have great impact on marketing and advertising and would have many beneficiaries for the marketers and advertisers. Since from the origin of internet and social media, many past studies and research work have been done on the role and effects of digital transformation on visual communication in the world till now. Nowadays digital advertising is mostly referring to social media advertisements. The social media is now used as a tool or business strategy to endorse and expand their business, gain more audience and engage their consumers with themselves. There are many social media 
websites used today for advertising of products and business expansion purposes such as Facebook, Twitter, Instagram, LinkedIn, Snapchat, Pinterest, Tumblr, Spotify and Foursquare (Korey C, 2015). In this paper, we will discuss only about Facebook advertising, how advertisers gain popularity and attention of consumers across cultures through their ads. It starts from the year 2007 and since then it is continuously developing with more new tools and advancements of technologies. The annual report of year 2018 shows that $90 \%$ people use Facebook for expanding their business and promotion of products through advertisements, which is much higher rate than other social media platforms (Matt, 2018). The main purpose of this digital advertising is to create brand awareness and build an engagement between consumers and advertisers on a low budget to wider audience (Dokyun, Kartik, \& Harikesh, 2018). It offers two basic advertisement campaigns for advertising of products good and services to advertisers i.e. Cold traffic campaigns and Remarketing campaigns. After the evolution of mobile phones technology and its apps downloading systems, Facebook advertising was shifted towards mobile phones in 2009 and gain its popularity and strength in the years $2010-2013$. It had been seen that in the year 2010, Facebook had over 517 million users (Kevin, Sarah, \& Christopher, 2011). Previous studies show that after the year 2012, Facebook advertising become more easy, efficient and user friendly for the advertisers and after 2016, 84\% of total ad profits was due to mobile phones advanced technology (Bamboo, 2017). It has been seen that the shifting of Facebook ads on mobile application technology helps advertisers to personalize their ads and share more information and content about their products, good and services with their customers and make different ads for their regular customers according to their tastes, requirements and values. It is a new strategy of advertisement campaigns that allow advertisers to engage and target cross-cultural audiences with themselves (Matt, 2014). Previous studies show that most of the customers want personalized ads. Personalized ads can be defined as the marketing strategy of advertisers that creates messages and contents for the individuals or specific customers by focusing on individual's needs and desires through cookies, beacons and feedback of individual customers. According to recent researches conducted in the year 2017 - 2018, 80\% people prefer personalized advertisements (Molly, 2017). As these ads are more relevant to the customer's choice, tastes and value, thus people are more attracted towards these ads and due to this personalization advertisers gain more consumer engagement than non- personalized ads. It also increases the chances of likeness attitude and purchasing response of customers (Kumar \& Shaphali, 2016).

\section{RESEARCH QUESTION}

Q. Can digital visual communication become successful in overcome cross cultural effects on product advertising?

\section{THEORETICAL FRAMEWORK}

The theory I selected for my research is information processing theory. This theory is developed by George A. Miller in 1956. The basic idea of information processing theory is work on three stages: At first stage informational data is gathered from the environment as input. The second stage stores and processed the information data by the brain. At the third stage, the stored and processed information is then delivering the result as output (David L, 2015). The phase of processing information is crucial part of the theory as it relates to the cognitive process of brain. This cognitive process depends on many factors like language, perception, values, knowledge, thinking, judging, imagination, 
remembering, recognition, visual perception, storage and many more like these (Goodwin, 2005).

Here I select this theory to test its working in visual perception of advertisement design. Visual perception is the result of complex interactions between external visual stimulus and prior knowledge, goals, and expectations. Understanding how we all perceive things visually will help designers to communicate better. The visual perception is of two types: one is the external and other is internal. The external perception is what we see in the world from our eyes and the internal perception is how we see the world; this word how is depend on many aspects like our knowledge, mood, cultural values, education etc. After we publish our advertisement design in front of our target audience or public, its success rate depends on how much it gains the attention and attraction of our audience. Then the audience attraction depends on the way they perceive it in their minds according to their depth of processing, schemas and mental models. The depth of processing depends on how deeply we saw the ad if we only see the physical appearance of advertisement design and do not pay any attention towards its meaning then we do not store the information and cannot recalled later. For example, focusing on the shapes and colors of a graphic is not as effective as studying the graphic and taking in the explanations of that graphic. We want to connect meaning to the aesthetic. Schemas are mental frameworks of information. They're abstract representations of what we know about the world and they become the context or frame for interpreting new information. Whereas, mental models are broader conceptualizations of how things work and they explain cause and effect. Designers should consider the schemas and mental models of their audience. While, we cannot know our audience's exact schema and mental model in advance, we can be aware of an audience's cognitive characteristics which can give us clues like create development level of our audience, create designs that distract less, bring visual literacy element in our design by using symbols, try to bring audience goals in our design, think of the differences in how colors are interpreted across cultures and lastly try to improve our reading skill in your design as this will help to gain audience attention towards ad. (Steven, 2011).

\section{METHOD}

Researcher has adopted the qualitative content analysis of three mobile phone companies (Huawei, Vivo and iPhone) advertisements in four different countries (Pakistan. China, India and USA) to analyze the effectiveness of digital transformation in marketing mobile phone advertisements. For this purpose, researcher take four mobile phone companies and compare their ads between two different countries about the same mobile company and analyze the impact of two types of elements of design in it i.e. picture and text. The first one is about Huawei Nova 3 advertisement campaign and its content analysis is between China and Pakistan shown below.
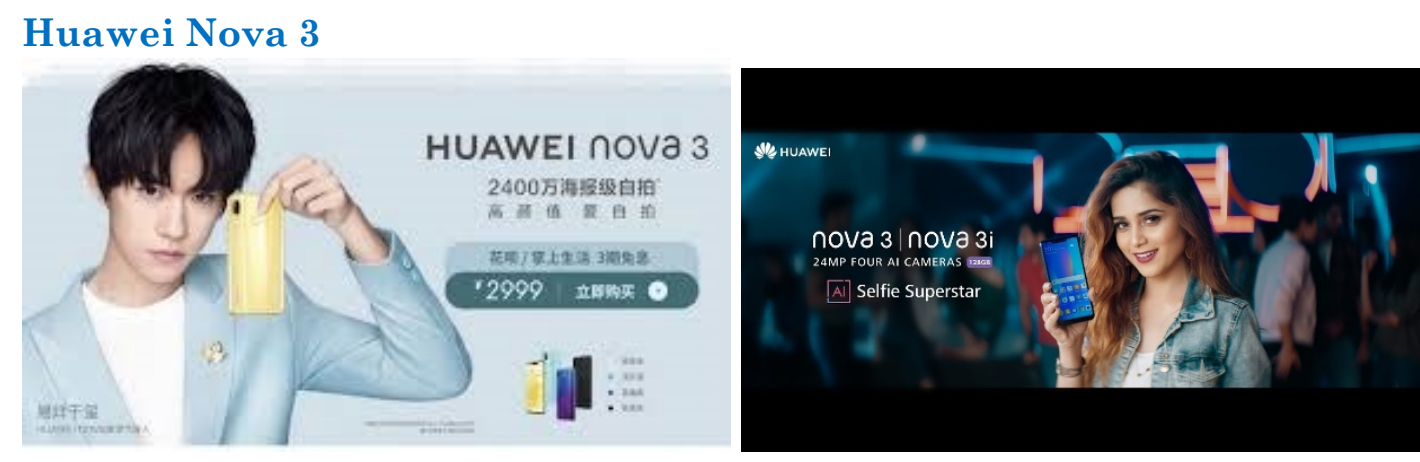
Picture: Picture has great importance in advertisement design, as most of the consumers are attracted towards the ad only because of image or picture and it also influence the cultural aspect as well in many advertisements. In the above two advertisements, picture has the ability to gain the center of attraction in consumer's eyes and it also represents the culture of both countries. The Huawei nova 3 ad for china is advertise by popular Chinese singer artist Lay Zhang while the Huawei nova 3 ad for Pakistan is advertise by Pakistani popular singer artist Aima Baig as shown in the above pictures.

Text: Text has also great importance in advertisement design because it describes the product's name, specifications and price in the market as shown in the above two figures. Hence the text should be readable and understandable by the target audience. In the above two advertisements, the text used in left advertisement picture is mostly in either Chinese language or English which is easily understandable by the Chinese people but not easily understandable for Pakistani people whereas the text used in the right side of advertisement is in International English which is also easily understandable for Pakistani people.

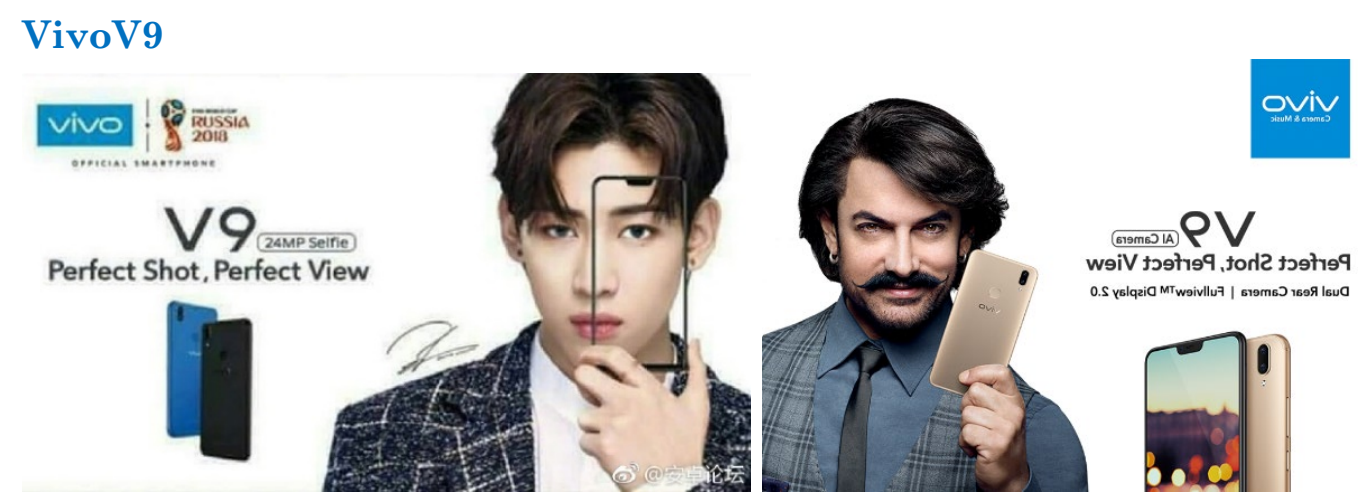

Picture: In the above two advertisements, the picture has same importance and impact on consumers eyes as it is shown in the advertisement 1 of Huawei nova 3 ad but the only difference is here in right side of advertisement picture represents the ad is for Indian audience as the picture is of Indian Film Star Amir Khan is showing the mobile ad whereas the left side of advertisement picture represents the ad is for Chinese audience as the picture is of Chinese actor Lay Zhang is showing the mobile ad.

Text: Here the text used is mostly in English which is easily understandable by the both country's audience as English is internationally recognized by all around the world. The other important thing which is notable in text is that in the Indian advertisement the text and company logo vivo is placed on the right side of picture as the rule of Hindi text language is to write from the right to left of the page whereas in the Chinese advertisement the text and company logo vivo is placed on the left side of picture as the rule of Chinese text language is to write from the left to right of the page. 

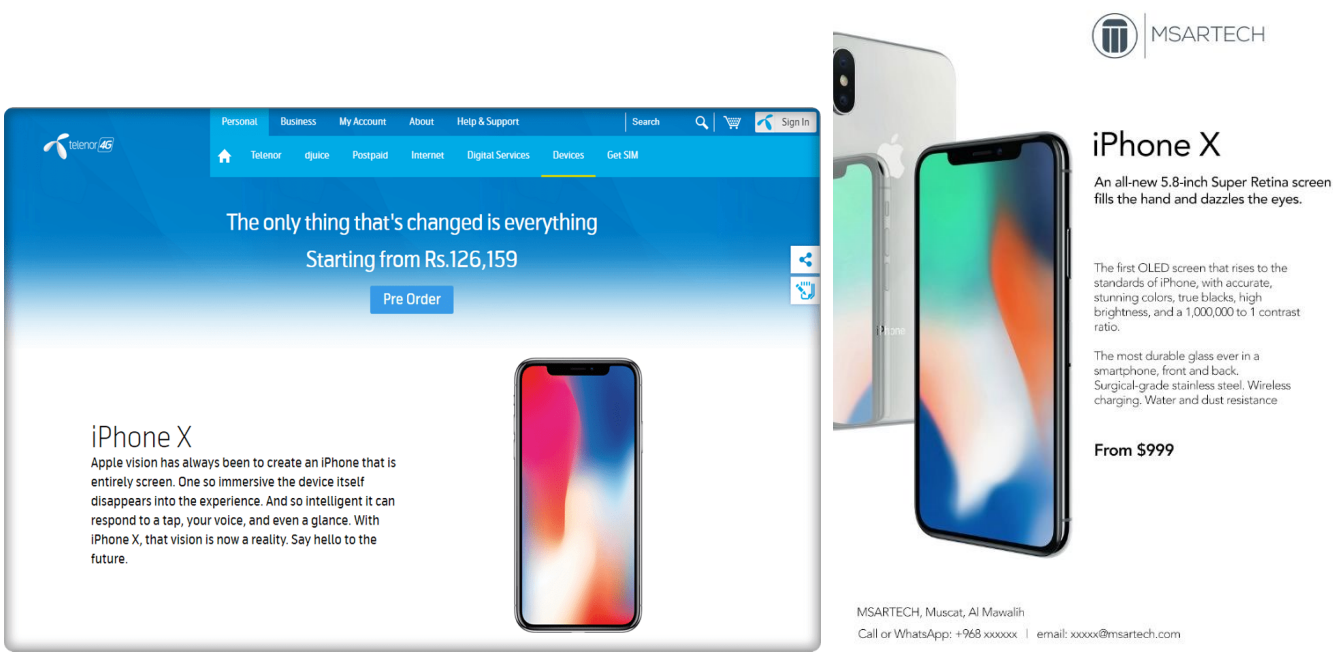

Picture: In the above two advertisements, the picture used in ads is almost same as it only shows the mobile but the text is different.

Text: Here the text used in both advertisements is although in same language (English) but the price and channel through which the ad is showing is different from one another as in the left side of advertisement picture the pakistani mobile network company Telenor is showing the iPhone $\mathrm{X}$ ad with price in Pak currency 126,159 Rs whereas in the right side of advertisement picture the USA company MSARTECH is showing the ad with price in US currency $\$ 999$.

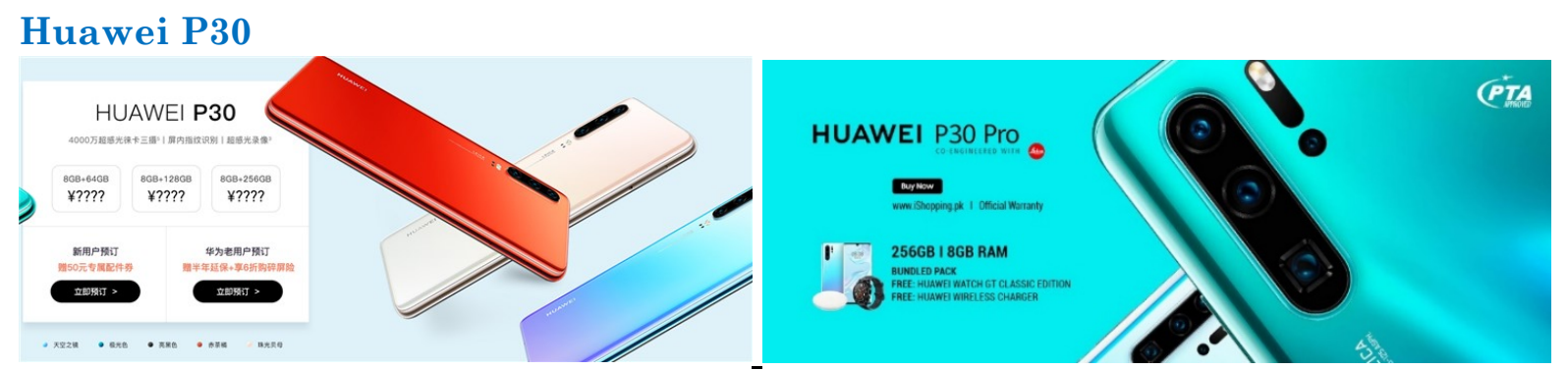

Picture: Here the picture used in ads is almost same as it only shows the mobile Huawei P30 but the text and language of text is different from one another.

Text: Here the text used in left advertisement picture is mostly in either Chinese language or English which is easily understandable by the Chinese people but not easily understandable for Pakistani people whereas the text used in the right side of advertisement is in International English which is also easily understandable for Pakistani people.

\section{RESULTS}

The above content analysis of mobile advertisements of international companies in different countries shows that due to the era of digital transformation in globalization, visual communication has also become more powerful than before and it also become very much successful in overcome cross-cultural effects such as language, text and improved picture quality but some other cross-cultural issues are still present even in digital era such as literacy and religion. Here we observe that to overcome the language issue in cross-cultural advertisements, advertisers adopted two types of strategies in text area: 
1. Use of international English writing in the text form.

2. Use of the national language in text writing of that country from whom they are targeting e.g if the target audience of advertisement is Chinese people the advertisers will write text in Chinese language in the ad so that it is easily understandable by their target audience.

However, in picture area advertisers take national heroes in ads to represent the nation and promote the products in audience.

\section{CONCLUSION}

From the above research, researcher concludes that before digital era, international advertising has gone through many difficulties like language, literacy, religion etc. in the communication process. Hence to overcome these problems digital era arrived around the year 2000. Nowadays Facebook is the most common tool used for digital advertising by the marketers and advertisers and it had also overcome many cross-cultural issues occurred in visual communication such as language problem. Now marketers adopted different strategies to create awareness, promote the product and boost sales of products in different countries from all around the world such as make separate Facebook pages for every country's audiences' and upload ads according to that country's audience's tastes and views. For example, if they want to promote the product in Pakistan and engage Pakistani audience with themselves then they make separate Facebook page for Pakistani audience and upload ads that are made according to the culture, needs and desire of Pakistani audience so that the ad is easily understandable for Pakistani people. Another most common strategy adopted by the marketers and advertisers who want to promote the product internationally is the use of international English and national language in text writing e.g., if the target audience of advertisement is Chinese people the advertisers will write text in Chinese language in the ad so that it is easily understandable by their target audience while in selection of picture advertisers take national heroes in ads to represent the nation and promote the products in audience.

\section{REFERENCES}

Alvarez, J. M. R. (2008). Effectiveness of values communication through cross-cultural corporate symbol design. Iowa State University.

Bradley, S. (2011, March 7). What Designers Should Know About Visual Perception and Memory. Retrieved from https://vanseodesign.com/web-design/visual-perceptionmemory/

Chi, H. H. (2011). Interactive digital advertising vs. virtual brand community: Exploratory study of user motivation and social media marketing responses in Taiwan. Journal of Interactive Advertising, 12(1), 44-61.

Curran, K., Graham, S., \& Temple, C. (2011). Advertising on Facebook. International Journal of E-business development, 1(1), 26-33.

David, L. (2015, December 4). Information Processing Theory. Retrieved from https://www.learning-theories.com/information-processing-theory.html

Design, G. (2014, March 11). What are the Elements of a Design? Retrieved from http://www.graphic-design-institute.com/blogs/what-are-elements-design

Dijck, J.V. (2013). The Culture of Connectivity: A Critical History of Social Media. Oxford: Oxford UP, 2013. Print. https://doi.org/10.1093/acprof:oso/9780199970773.001.0001

Douglas, S. P. \& Craig, C. S. (2003). International Advertising. Retrieved from http://pages.stern.nyu.edu/ sdouglas/rpubs/intad.html 
Online Journal of Communication and Media Technologies, 2019

Dyer, G. (2008). Advertising as communication. Routledge.
https://doi.org/10.4324/9780203158340

Edu, H. (2013). Elements of Design. Retrieved from http://www2.hawaii.edu/ meidor/art_101/elements_of_design.html

Essays, UK. (November 2018). International Advertising as a Communication Process Marketing Essay. Retrieved from https://www.ukessays.com/essays/marketing/ international-advertising-as-a-communication-process-marketing-essay.php?vref=1

Faheemullah, \& Yousaf, S. (2017). The Consumer Attitude towards Social Media Advertising and the Influence of Corporate Reputation on Consumer Response. Assumption University-eJournal of Interdisciplinary Research, 2(2).

Galetto, M. (2017, March 06). What Is Personalized Marketing? A Look at How Personalized Marketing Works, Benefits, Best Practices, and More. Retrieved from https:/www.ngdata.com/what-is-personalized-marketing/

Gowda, S. (2011, April 27). Advertising and Culture. Retrieved from https://www.slideshare.net/sukeshgowda/advertising-and-culture

Hogenkamp, A. N. (2015). Influence of advertising design and featured product on consumer's perceived mood and evaluations (Master's thesis, University of Twente).

Kumar, V., \& Gupta, S. (2016). Conceptualizing the evolution and future of advertising. Journal of Advertising, $302-317$. https://doi.org/10.1080/00913367.2016.1199335

Leiss, W., Kline, S., Jhally, S., \& Botterill, J. (2013). Social communication in advertising: Consumption in the mediated marketplace. Routledge. https://doi.org/10.4324/9780203943014

Liu, B., \& Liu, F. (2016). Research on the Development Trend of Visual Communication Design Education in the Cultural and Creative Industries in 2016 International Conference on Education, Management Science and Economics. Atlantis Press. https://doi.org/10.2991/icemse-16.2016.14

Love, K. C. (2015). Social Media and the Evolution of Social Advertising through Facebook, Twitter and Instagram.

Luo, M. (2017). Exploring the Practice of Visual Communication Design in the New Era Based on the View of "Art+ Technology". Asian Journal of Social Science Studies, 2(3), 8. https://doi.org/10.20849/ajsss.v2i3.175

Malthouse, E. C., \& Calder, B. J. (2018). From Advertising to Engagement. The Handbook of Communication Engagement, 411-420. https://doi.org/10.1002/9781119167600.ch28

Maori, R. (2012, December 15). Design and Visual communication. Retrieved from https://technology.tki.org.nz/Technology-in-the-NZC/Technology-indicators/ Indicators-Learning-Objectives/Design-and-Visual-Communication

Negm, E., \& Tantawi, P. (2015). Investigating the Impact of Visual Design on Consumers' Perceptions towards Advertising. International Journal of Scientific and Research Publications, 5(4).

Pompa, M. (2018). The Complete Guide to Advertising on Facebook: Strategies That Convert [in 2019]. Retrieved from https://www.bigcommerce.com/blog/facebookadvertising-guide/

Quintero, C. (2017, June 28). How our Visual Culture is Shaping the Future of Digital Marketing. Retrieved from https://www.richclicks.co.uk/visual-digital-culture/ 
Samuel, U. (2016, March 10). Visual Communication of Popular Culture and Its Influence on Advertising and Branding in Digital Media. Retrieved from https://www.researchgate.net/publication/308063188_Visual_Communication_of_Po pular_Culture_and_Its_Influence_on_Advertising_and_Branding_in_Digital_Media

Sharma, A., Bhosle, A., \& Chaudhary, B. (2012). Consumer perception and attitude towards the visual elements in social campaign advertisement. IOSR Journal of Business and Management (IOSRJBM), 3(1), 6-17. https://doi.org/10.9790/487X0310617

Sherwin, R. K., Feigenson, N., \& Spiesel, C. (2006). Law in the digital age: How visual communication technologies are transforming the practice, theory, and teaching of law. BUJ Sci. \& Tech. L., 12, 227. https://doi.org/10.2139/ssrn.804424

Southern, M. (2014, July 23). New Facebook Ad Targeting Lets You Target Users by Device. Retrieved from https://www.searchenginejournal.com/new-facebook-ad-targetinglets-target-users-device/112375/\#close

Stephen, A. T. (2016). The role of digital and social media marketing in consumer behavior. Current Opinion in Psychology, 10, 17-21. https://doi.org/10.1016/j.copsyc.2015.10.016

Tayebi, S. S. (2010). The effectiveness of design elements like picture, text and color in aesthetic products advertisement. (Comparing advertisement in two countries of Iran and Sweden).

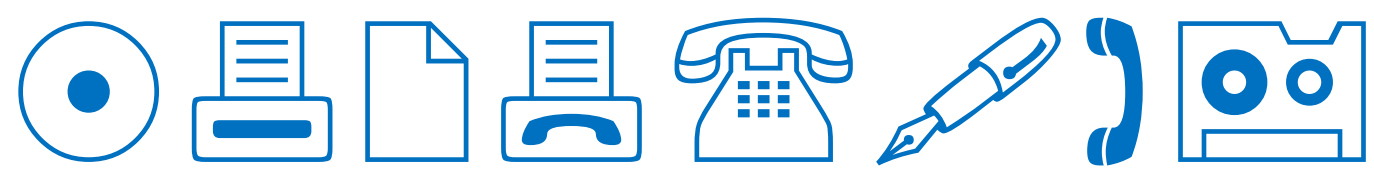

